\title{
Autobiographical memory for emotional events in amnesia
}

\author{
Irene Daum ${ }^{1}$, Herta Flor ${ }^{1,2}$, Susann Brodbeck ${ }^{1}$ and Niels Birbaumer ${ }^{1,3}$ \\ $1 /$ nstitute of Medical Psychology and Behavioural Neurobiology, University of Tübingen, \\ Tübingen, ${ }^{2}$ Department of Psychology, Humboldt University, Berlin, Germany, and \\ ${ }^{3}$ Dipartimento di Psicologia Generale, Universita degli Studi di Padova, Italy \\ Correspondence to: Irene Daum, Institute of Medical Psychology and Behavioural \\ Neurobiology, University of Tübingen, Gartenstr. 29, 72074 Tübingen, Germany
}

\begin{abstract}
This study investigated autobiographical memory for emotionally flavoured experiences in amnesia. Ten amnesic patients and 10 matched control subjects completed the Autobiographical Memory Interview and three semi-structured interviews which assessed memory for personal events associated with pain, happiness and fear. Despite retrograde amnesia for autobiographical facts and incidents, amnesics remembered a similar number of emotionally significant personal experiences as control subjects. Their recollections generally lacked elaboration and detail, but pain-related memories appeared to be more mildly impaired than memories associated with happiness and fear. The findings are discussed in relation to recent views on the relationship between affect and memory.
\end{abstract}

Keywords: Amnesia - Autobiographical memory - Emotional events

\section{INTRODUCTION}

Retrograde amnesia is characterized by a memory loss for past life experiences. Amnesia is usually not complete, as brain damage typically affects some types of old memories more than others. Remote semantic memory is often seen to be better preserved than old episodic memories, and amnesic patients typically show a gradient which documents a differential disruption of memory for recent relative to early experiences (Butters and Cermak, 1986; MacKinnon and Squire, 1989).

In current memory taxonomies, autobiographical memory is considered a subsystem of episodic memory (Nelson, 1989). Recent clinical studies have indicated, however, that autobiographical memory may have both semantic and episodic components. Patients suffering from organic amnesia often retain a knowledge of the general outline of their past, e.g. data concerning their education, career and family (Baddeley, 1990). Recollection of important personal events, however, lacks elaboration and detail, and a patient may describe his former life "as if he had a skeletal 'C.V.' which he could not elaborate" (McCarthy and Warrington, 1990; p. 307). This distinction between relative sparing of semantic personal facts and deficient recollection of specific occasions has been supported by a number of clinical investiga-

(C) 1996 Rapid Science Publishers tions (Tulving et al., 1988; Kopelman et al., 1990). A notable exception to this pattern was described by De Renzi and coworkers (1987). Their patient showed general preservation of both semantic and episodic biographical information, whereas non-biographical information was severely impaired. A more detailed evaluation of the status of autobiographical memory in amnesia and its role in memory taxonomies is difficult at present, as relatively few clinical studies have focused on recollections of the personal past and the results have been inconsistent (Conway, 1990).

There is, however, a general agreement that particularly vivid or emotional memories may have a special place in the organization of autobiographical memory (see Robinson, 1992), and recent research has concentrated on the interaction between information processing and non-cognitive factors such as emotions and moods (Baddeley, 1990). In an investigation using a diary procedure, Linton (1975) reported that pleasant events were better remembered than unpleasant or neutral incidents. In a further diary study, Wagenaar (1986) observed that at long retention intervals of several years, incidents with high emotional involvement were recalled at a much higher rate than neutral events, irrespective of the 
positive or negative content. It is well known that very strong negative emotions may lead to retrograde amnesia in individual cases ('psychogenic amnesia', see Markowitsch, 1994), but memory for traumatic experiences can be surprisingly vivid, and significant correlations were found between the intensity of the traumatic experience and the number of central details that were reproduced (Christianson and Loftus, 1990). Painful experiences also appeared to be remembered well, as the pain ratings taken retrospectively one week after a medical procedure were very similar to the initial ratings (Hunter et al., 1979). It should be noted, however, that memory for pain was found to be related to factors such as mood, type of memory task and pain status (Erskine et al., 1990). In a review of the literature on the relationship between affect and memory, Markowitsch (1994) stressed that cognitive and affective mechanisms are closely interwoven and that there is substantial overlap of the brain systems involved in emotional and memory processing, as evident from the wealth of data on the functional role of the limbic system. The tight interaction of these systems may underlie the finding that personal experiences are remembered best if their content is highly emotional (Wagenaar, 1986).

In addition to the studies in normal subjects, there is evidence that patients suffering from amnesia as a consequence of brain damage may show some degree of retention of emotionally flavoured stimuli or incidents. Implicit memory studies have documented that amnesics later prefer previously seen items with positive associations and they avoid stimuli which had been associated with negative experiences or pain, despite a lack of conscious recollection of the same stimuli (e.g. Claparede, 1911; Johnson et al., 1985). Severely amnesic Korsakoff patients may even show some preserved declarative memory for emotionally significant episodes (Zola-Morgan and Öberg, 1980), and it has been argued that spared memory in brain-damaged patients depends to a high degree upon an emotional flavouring (Markowitsch, 1994).

Several authors have emphasized the adaptive value of the capacity to retain memories of emotional and stressful experiences in particular, as remembering their context may help to avoid similar negative experiences in the future (Squire, 1987; Markowitsch, 1994). In a discussion of the mechanisms underlying memory for highly emotional experiences. Squire (1987) pointed to the possible role of peripheral hormones in the formation of particularly vivid recollections. A recent study by Cahill and coworkers (1994) supported this assumption. Propranolol, a betaadrenergic receptor antagonist, significantly impaired memory for an emotionally arousing but not for an emotionally neutral story.

As pointed out above, studies on autobiographical memory in amnesia are sparse, and reports of spared memory for incidents associated with strong emotions are often anecdotal or based on single cases. The main aim of the present study was to investigate further memory for positively and negatively flavoured autobiographical events in a group of amnesic patients. As tapping recollections in an unconstrained manner by cue word techniques is considered a particularly productive strategy in accessing autobiographical memory (see Robinson, 1992), semistructured interviews were devised which used emotions as cue words to evoke any memory associated with such cues. A further objective was to explore whether - similar to memory for generally neutral autobiographical events - a distinction could be drawn between preserved knowledge of personal facts and impaired recollection of specific incidents associated with emotions.

\section{METHOD}

\section{Subjects}

Ten patients with organic amnesia (group AMN) of differing aetiologies took part in this study. Four patients had Korsakoff's syndrome, two patients were amnesic because of ischaemic damage to the anterior thalamus (bilateral or unilateral right lesions). Three patients had suffered bilateral damage to the medial temporal lobe area as a consequence of encephalitis, contusion or early stage Alzheimer's disease. In a further patient, damage to the left temporal lobe had resulted from contusion. With the exception of the Korsakoff patients, CT and MRI scans were available to document the site of brain damage.

Ten normal control subjects (group NC) were selected from a larger subject pool to match to the amnesics in terms of age and general intellectual ability. None of the NC subjects had a history of psychiatric or neurological illness or took medication at the time of testing.

A battery of clinical memory tests was administered to both groups in order to obtain an indication of the degree to which the patients sample was memory-impaired. All participants completed a short version of the German Wechsler Adult Intelligence Scales (WIP; Dahl, 1972) and a mood rating scale. Mood was assessed with the Bond-Lader Visual Analogue Scales (Bond and Lader, 1974). These scales have been widely used as measures of present-state 
TABLE I. Mean scores for amnesics and matched control subjects for age, affect-arousal ratings, IQ and different memory tests (SDs in brackets)

\begin{tabular}{lrrrr}
\hline & Amnesics & \multicolumn{1}{c}{ Controls } \\
\hline Age & $53.2(12.2)$ & $53.6(11.5)$ \\
Affect-arousal score & $39.8(21.6)$ & $33.8(12.9)$ \\
IQ & $99.8(6.4)$ & 104.7 & $(6.7)$ \\
Story - immediate & $5.0(2.7)$ & 10.7 & $(2.7)$ \\
Story - delayed & $1.8(2.1)$ & $8.4(3.0)$ \\
Word lists - immediate & $12.4(4.7)$ & $20.4(5.2)$ \\
Word lists - delayed & $1.6(2.1)$ & $9.8(3.8)$ \\
Benton - correct & $3.5(2.3)$ & $6.5(1.8)$ \\
Benton - errors & $12.8(5.7)$ & 5.1 & $(3.2)$ \\
Rey - \% recall & $31.0(8.4)$ & 74.6 & $(3.4)$ \\
\hline
\end{tabular}

anxiety and depression, and they have also been shown to be significantly related to cognitive impairment in neurological patients (see Brown et al., 1984). The scales comprise 16 pairs of adjectives relating to affect and arousal (such as "happy-sad", "lethargicenergetic"). The pairs are joined by a $100 \mathrm{~mm}$ line and the subjects are instructed to indicate the position that best describes their present state.

To assess verbal memory, subjects were asked to recall a prose passage from the Wechsler Memory Scale (WMS; Böcher, 1963) immediately after presentation and after a delay of $1 \mathrm{~h}$. In addition, immediate and delayed free recall of three 16-item word lists was assessed (see Daum et al., 1993). Visuo-spatial memory abilities were measured by means of the Benton Test (Benton, 1955) and by delayed reproduction of the Rey-Osterrieth Figure (Osterrieth, 1944).

The mean scores of the amnesic patients and the matched controls for age, IQ, mood rating and the different memory tests are given in Table I.

The amnesic patients did not differ significantly from the NC group on age $(p=0.94)$, the affectarousal rating $(p=0.46)$ and IQ $(p=0.11)$, but showed a significantly poorer performance on all memory measures (all $p<0.006$ ). As can be seen in Table I, the average memory scores of the amnesic patients lay approximately 1.5 to 2 standard deviations below the means of the control subjects, and performance on delayed recall tests was particularly poor. This pattern of results confirmed the presence of an amnesic syndrome in the group of braindamaged patients who participated in this study.

\section{Materials}

Autobiographical memory interview. All subjects completed the Autobiographical Memory Interview developed by Kopelman et al. (1990). The unpublished German version used in the present investiga- tion was translated from the original version and applied to clinical studies with German speaking patients by Markowitsch and coworkers (1993). The Autobiographical Memory Interview is a semistructured interview consisting of two parts. The first part assesses personal semantic memories of facts from the subject's past life (e.g. names and places of schools, previous addresses, date and place of wedding etc.). The second part probes memory for specific autobiographical incidents, such as recollection of a specific event during the wedding celebration or of a specific event during the last holiday. Autobiographical facts and incidents are assessed separately for childhood, early adulthood and the recent past. For each period, a maximum score of 21 points can be achieved for personal facts and a maximum score of 9 for recall of autobiographical incidents. Thus, the overall maximum scores are 63 for personal semantic facts and 27 for autobiographical incidents.

Autobiographical memory for emotional experiences. In the present study, specific emotions were used as cues and the subjects were asked to produce any memories of autobiographical incidents that were evoked by these cues. These semi-structured interviews were based on the procedure used in the 'Autobiographical Memory for Pain Interview' by Flor and coworkers (1996). All subjects completed three different interviews; they assessed memory of personal incidents associated with pain, happiness and fear, respectively. No time restrictions were given.

Recall of autobiographical experiences associated with pain, happiness and fear. At the beginning of each interview, subjects were asked to produce recollections of personal experiences associated with the respective emotion. The following instructions were given: "Please describe all situations that you remember in which you experienced pain (happiness, fear)". If subjects provided a fact without any more detailed information (e.g. "The car accident"; "When I met my wife"), probe questions were asked to aid recollection of more specific details (concerning the subject's age at that time, the preceding situation, the duration and the consequences of the incident). The subject then had to rate the intensity of his/her emotion during each event on a visual analogue scale. The end points of the respective scale were "no pain (happiness, fear)" and "intense pain (happiness, fear)". These points were joined by a $100 \mathrm{~mm}$ line, and the subject had to indicate the position that best described the intensity of his/her emotional experience. 
Childhood memories of emotional events. In the second part of each interview, subjects were told that children may have a different concept of pain (happiness, fear) than adults and that children may experience pain (happiness, fear) in other situations than do adults. They were then asked to try to remember situations from their childhood in which they, but not necessarily other people had experienced pain, happiness or fear, respectively. No age range was given to specify 'childhood'; subjects generally reported events that they experienced when they were 14 or younger.

Mental imagery of emotional events. In the final part of each interview, subjects were instructed to imagine situations that are generally associated with pain, happiness or fear. A brief description of each situation was read, and the subjects were then asked to describe how they would feel if they were experiencing the respective event. The following situations were used to induce imagery. PAIN: 1. "Imagine you are at the dentist's, he is drilling without having given you an anaesthetic and his drill is touching a nerve". 2. "Imagine that several parts of your body are on fire, for example after a car accident". HAPPINESS: "Imagine you have applied for a job that you really want very much and you have just been told that you got the job". 2. "Imagine you have just fallen in love". FEAR: 1. "Imagine you are standing on top of a church tower looking over the railing, and you notice that the railing is broken." 2 . "Imagine that in five minutes time you are going to have a very important job interview".

After the subjects had described their thoughts and feelings, they were asked whether or not they had experienced such an incident in their own lives.

\section{Scoring}

The interviews were scored according to a procedure which had been evaluated in several samples of chronic pain patients and healthy control subjects (see Flor et al., 1996). Two independent raters scored the interview data. In rare instances the scores of the two raters differed by 1 or 2 points; in these cases the scores were averaged. Even though scoring was intended to be done blind, the raters identified the interview of many amnesics by their lack of detail.

For each subject, the overall number of incidents associated with pain, happiness or fear reproduced during initial free recall were recorded. In order to assess the quality and detail of each memory, each incident was analysed further by establishing the number of details relating to the context of the event (place, time, people involved) and by noting the number of details concerning the subjective experience itself. The latter involved cognitive items such as thoughts (e.g. "I wondered how to tell my wife"), affective details (e.g. "It was unbearable", "It was overwhelming") and sensory details or physiological responses (e.g. "Pulsating pain", "I felt dizzy"). The reports for mental imagery were analysed with respect to the overall number of details (thoughts, affective or sensory-physiological descriptions) produced by the subject. The small number of elements reported by both groups during imagery did not allow a separate analysis of cognitive, affective and physiological items.

\section{Statistical analysis}

There were significant differences in variances both between the two groups and between repeated measures within groups on most autobiographical memory variables. These findings precluded statistical analysis by means of parametric tests. Between and withingroup differences were therefore evaluated by non-parametric tests (Mann-Whitney $U$ tests and Wilcoxon tests) in all analyses.

\section{RESULTS}

\section{Autobiographical memory interview}

The results for the Autobiographical Memory Interview in the amnesic patients and the control group are depicted in Fig. 1.

The amnesic patients showed poorer recall of autobiographical facts and incidents than control subjects for all stages of their life ( $\mathrm{U}$ tests, all $p<0.007$ ). In the patient group, personal facts from childhood were recalled better than facts from the recent past $(z=-1.99, p=0.47)$, whereas the opposite pattern was seen in the control group $(z=2.03, p=0.042)$. Memory for autobiographical incidents was poor in the amnesic patients, irrespective of the time period involved. Control subjects, on the other hand, showed better recall of events from their recent past and early adulthood compared to childhood (both $z>1.82, p<0.042$ ).

When the data for the different time periods were pooled and analysed in terms of proportions of maximum scores, amnesic patients scored $63.1 \%$ (SD = 18.0) for semantic facts and $31.7 \%(\mathrm{SD}=19.6)$ for autobiographical incidents; the respective data for control subjects were $96.7 \%(\mathrm{SD}=4.6)$ for facts and $94.8 \%(\mathrm{SD}=6.3)$ for incidents. Although the level of recall of facts and incidents did not differ in the control subjects $(p=0.16)$, amnesic patients showed significantly better recollection of personal semantic 


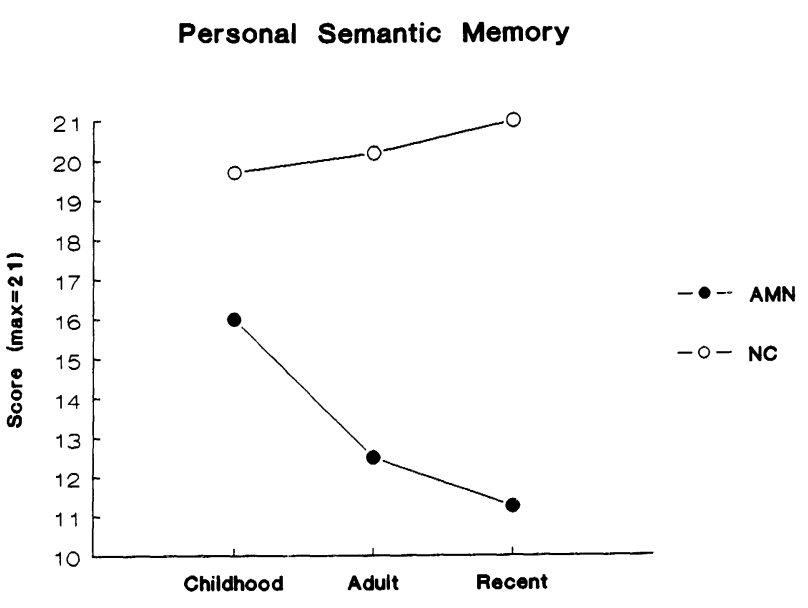

Autobiographical Incidents

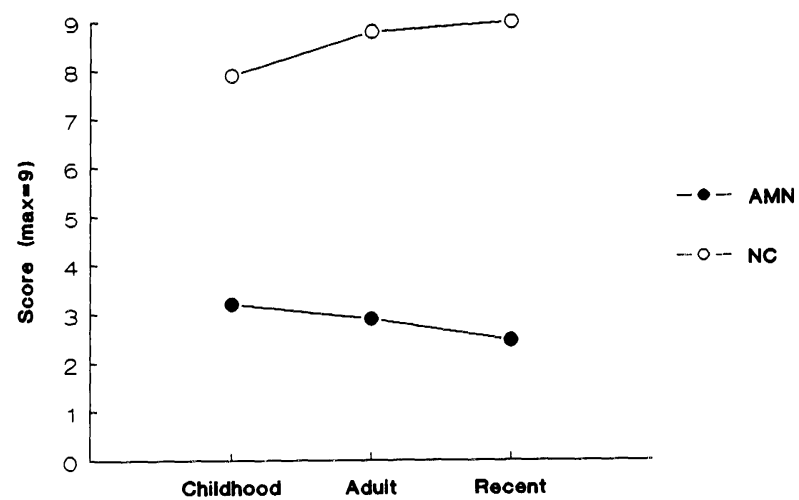

FIG. 1. Mean scores in the Autobiographical Memory Interview in the group of amnesic patients (AMN) and the control group (NC).

facts compared to autobiographical events $(z=2.80$, $p=0.005$ )

\section{Autobiographical memory for experiences associated with pain, happiness and fear}

Information on the mean number of incidents recollected in response to the different cue emotions is presented in Fig. 2.

The amnesic patients and the control subjects did not differ significantly in the overall number of autobiographical incidents which they remembered with respect to pain, happiness or fear (all $p>0.12$ ). The mean intensity ratings in the amnesics were 61.5 $(\mathrm{SD}=23.4)$ for pain, $59.5(\mathrm{SD}=35.4)$ for happiness and $56.6(\mathrm{SD}=24.8)$ for fear. The respective scores of the control subjects were $54.7(\mathrm{SD}=20.8)$ for pain, $71.3(\mathrm{SD}=19.7)$ for happiness and 64.8 $(\mathrm{SD}=15.9)$ for fear. There were no significant group

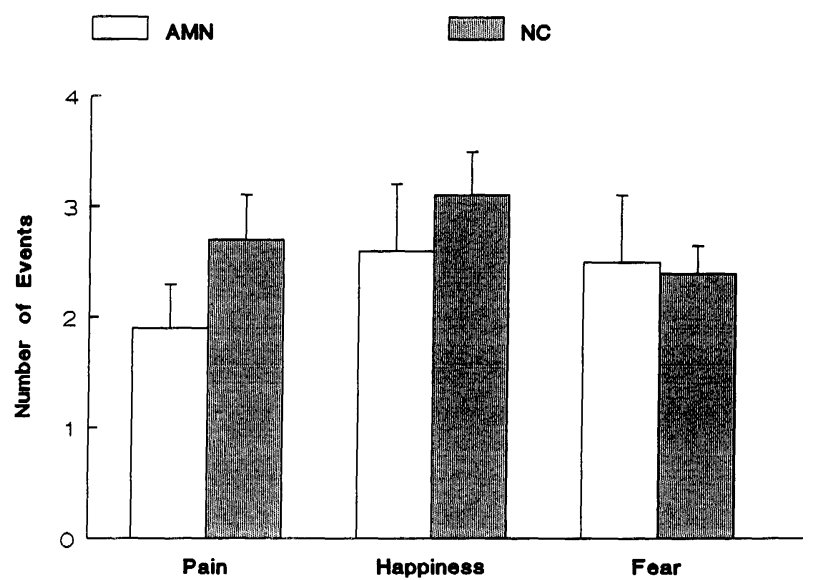

FIG. 2. Mean number of autobiographical events recalled in association with pain, happiness and fear (+ SEMs) in amnesic patients (AMN) and control subjects (NC).

TABLE II. Mean number of contextual details and mean number of details relating to the personal experience in the reports of emotionally flavoured memories (SDs in brackets)

\begin{tabular}{lccc}
\hline & Pain & Happiness & Fear \\
\hline Context & & & \\
Amnesic patients & $2.26(2.1)$ & $0.35(0.4)$ & $1.21(2.1)$ \\
Control subjects & $3.81(3.6)$ & $1.31(1.2)$ & $3.76(2.6)$ \\
Personal experience & & & \\
$\quad$ Amnesic patients & $0.87(1.0)$ & $0.60(0.7)$ & $0.43(0.7)$ \\
Control subjects & $4.00(2.4)$ & $2.83(2.1)$ & $2.36(1.4)$ \\
\hline
\end{tabular}

differences concerning the experienced intensity for any of these categories (all $p<0.43$ ).

Further analyses were carried out concerning the content of the reports, i.e. the mean number of contextual details and the mean number of items describing the personal experience of the subject. The results are presented in Table II.

When the data from the initial free recall part are considered, the amnesic patients recalled fewer contextual details of personal events associated with happiness $(U=21.5, p=0.027)$ and fear $(U=11.0, p=$ 0.003 ) than the control subjects, while there was no significant group difference for painful incidents $(p=0.31)$. The same pattern of results was obtained when contextual elements recalled in response to the different cue questions (age, duration etc.) were added to these scores. Within-group analyses showed that both amnesics and control subjects remembered more details about pain-related and fear-related events than about events associated with happiness (all $z>2.0, p<0.048$ ), whereas there were no significant differences between pain-related and fear-related 


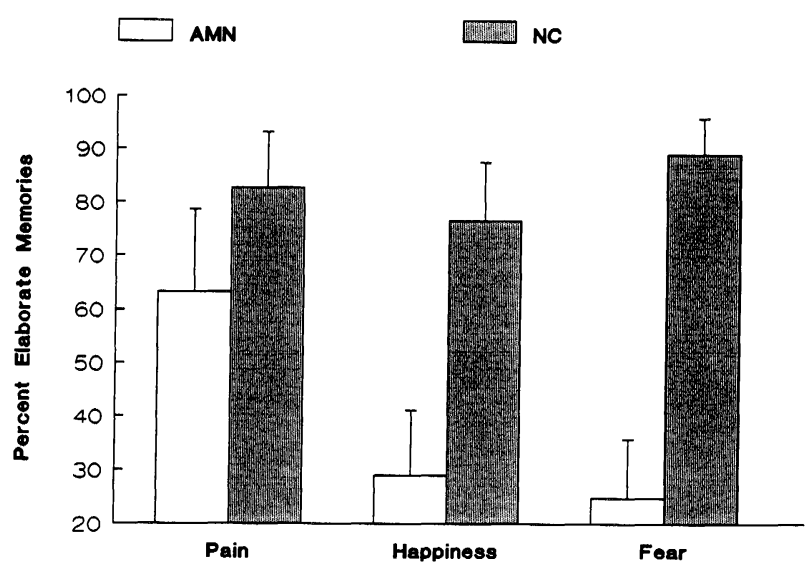

FIG. 3. Mean proportions of elaborate memories (+ SEMs) relative to the overall number of memories in amnesic patients (AMN) and control subjects (NC).

details in either group $(p=0.20$ and $p=0.90$, respectively). It should be noted that despite the lack of a statistically significant group difference for painful events which emerged in non-parametric analysis, the absolute difference in the number of contextual details was considerable and in the range of the significant difference for events associated with happiness.

Analysis of details relating to contents associated with the subjective experience indicated that for each category of emotions, amnesics remembered a significantly smaller number of details than control subjects (all $p<0.011$ ). Within-group analyses indicated that amnesics remembered a similar number of details relating to pain, happiness and fear, while the control subjects remembered more details of experiences related to pain as compared to experiences related to happiness $(p=0.038)$.

This general pattern indicates that although both groups recalled a similar number of emotionally flavoured autobiographical incidents, the amnesic patients had much vaguer memories than the control subjects. To evaluate the incidence of more elaborate memories, the frequency of reports for which an incident (e.g. "My first date with my girlfriend" or "The car accident") was qualified by at least two further details was assessed. Figure 3 illustrates the proportion of elaborate memories relative to the overall number of memories for each category of emotional memories.

As illustrated in Fig. 3, the two groups did not differ significantly in the proportion of more elaborate memories of painful experiences $(p=0.13)$, while the amnesics showed a smaller proportion of elaborate memories for events associated with happiness $(U=17.0, p=0.01)$ and fear $(U=7.0, p=0.001)$. The amnesic patients showed a higher proportion of
TABLE III. Mean proportions of childhood incidents relative to the overall number of incidents reported in a free recall condition (SDs in brackets)

\begin{tabular}{lccc}
\hline & Pain & Happiness & Fear \\
\hline $\begin{array}{c}\text { Amnesic } \\
\text { patients }\end{array}$ & $53.3 \%(14.2)$ & $18.8 \%(9.7)$ & $42.0 \%(13.9)$ \\
$\begin{array}{c}\text { Control } \\
\text { subjects }\end{array}$ & $13.7 \%(6.0)$ & $11.2 \%(4.7)$ & $32.5 \%(10.9)$ \\
\hline
\end{tabular}

more elaborate memories for painful experiences compared to experiences associated with happiness $(z=$ 2.03, $p=0.042)$ and fear $(z=1.84, p=0.066)$, whereas there was no such differential pattern in the data of the control subjects.

To assess whether the more elaborate pain-related memories were less impaired in the amnesics than the other categories of emotionally flavoured memories, the deviation of each patient's scores from the controls' scores was determined in terms of $z$ scores. The mean $z$ scores were $z=-0.6$ for pain-related memories, $z=-1.4$ for memories related to happiness and $z=-3.1$ for fear-related memories. Pain-related memories were significantly less impaired than fearrelated memories $(p=0.001)$ and showed a tendency towards better preservation relative to memories associated with happiness $(p=0.09)$.

\section{Childhood memories of emotional events}

Analyses of the data from the Autobiographical Memory Interview had indicated that amnesic patients, unlike control subjects, showed better recollection of childhood relative to more recent events. In order to determine whether a similar pattern might be seen in the memories for emotional experiences, the reports from the initial free recall part of the interviews focusing on pain, happiness and fear were analysed with respect to the proportion of autobiographical events dating from childhood. The results are presented in Table III.

Across categories, $39.4 \%(\mathrm{SD}=30.6)$ of all personal incidents remembered by the amnesic patients were childhood events, whereas only $19.1 \%$ (SD = 17.7) of reports dated back to childhood in the control group. This difference did, however, not reach statistical significance $(U=49.5, p=0.156)$. Analyses of the individual categories indicated that amnesic patients reported significantly more childhood incidents than controls in the category 'pain' $(U=75.0, p=$ $0.046)$, but not in the other two categories $(p>0.64)$. The childhood memories did, however, not contain more detail or a higher proportion of elaborate descriptions than those from adult life (all $p>0.20$ ).

62 Behavioural Neurology . Vol 9.1996 
TABLE IV. Mean number of childhood incidents associated with pain, happiness and fear (SDs in brackets)

\begin{tabular}{lccc}
\hline & Pain & Happiness & Fear \\
\hline Amnesic patients & $1.5(1.3)$ & $1.3(1.2)$ & $1.8(2.4)$ \\
Control subjects & $2.2(1.3)$ & $3.4(1.9)$ & $2.5(1.4)$ \\
\hline
\end{tabular}

Whereas the first part of the interview for autobiographical memories associated with pain, fear and happiness referred to any event the subjects remembered, the second part of each interview specifically addressed childhood events associated with the respective emotions. The mean number of childhood incidents are summarized in Table IV.

The data presented in Table IV reveal that amnesics and control subjects did not differ in the number of specific childhood memories relating to pain $(p=$ $0.26)$ and fear $(p=0.11)$, while the controls remembered a significantly larger number of happy events $(U=19.5, p=0.018)$. The same pattern of results was obtained when the childhood incidents which were reported during the initial free recall part and not repeated when childhood memories were specifically assessed were added to the scores obtained with the childhood memory instruction. Both groups recalled a numerically similar number of childhood experiences associated with pain and fear $(p>0.44)$; the control group did, however, remember a larger number of happy events $(U=22.0, p=0.031)$. Because of the small number of elaborate descriptions in both groups, further analyses relating to detail and vividness were not carried out.

\section{Mental imagery of emotional events}

The number of elements (i.e. thoughts, feelings, physiological responses) used by the two groups to describe mental imagery of episodes associated with pain, happiness or fear is illustrated in Fig. 4.

The amnesic patients did not differ significantly from the control group in the description of imagery of painful or fear-inducing situations (both $p>0.18$ ) and produced only marginally fewer details when imagining happy experiences $(U=26.0, p=0.068)$. Within-group analyses revealed that whether or not amnesics or control subjects had experienced the painful or happy situations themselves did not affect the number of items produced during mental imagery of these situations (all $p>0.34$ ). Both groups, however, reported significantly more details when they imagined situations associated with fear that they had lived through in their own life compared to fearinducing situations that they had not experienced

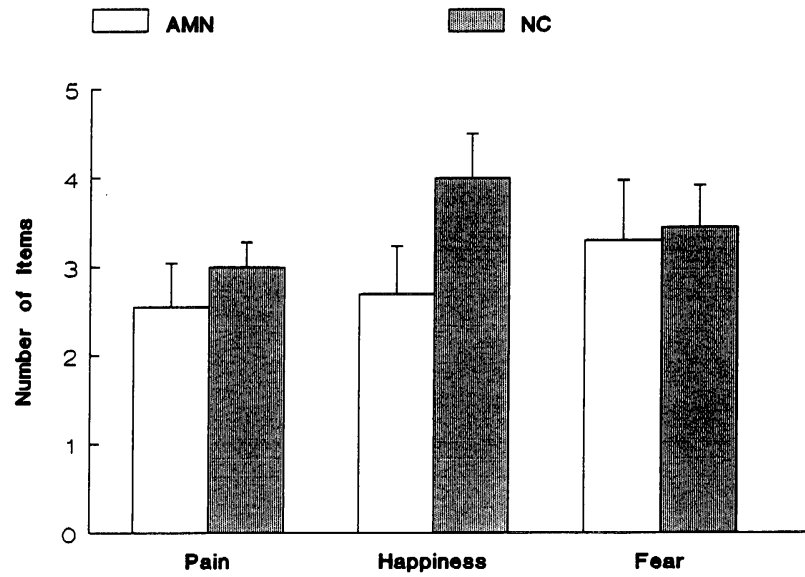

FIG. 4. Mean number of items (+ SEMs) used to describe mental imagery of situations associated with pain, happiness and fear in amnesic patients (AMN) and control subjects (NC).

themselves (amnesic patients: $z=1.98, p=0.047$; control subjects: $z=2.04, p=0.041$ ).

\section{DISCUSSION}

The main objective of the present study was to investigate emotionally flavoured autobiographical memory in amnesia. On the basis of prior clinical studies and theoretical considerations on the relationship between memory and affect (see Markowitsch, 1994), it was expected that personal memories associated with strong emotions may be partly spared in amnesic patients.

Autobiographical memory has rarely been investigated in brain-damaged patients, which may be due to the lack of experimental control and the difficulty in verifying their recollections. In the present study, it was possible to check the reports of the amnesic patients with their relatives in many cases. An additional concern relates to the effect of confabulation on the descriptions of autobiographical incidents. Confabulations about an imaginary past are rare and thought to be contingent upon extensive bilateral damage to the frontal lobes (Baddeley and Wilson, 1986). Confabulatory responses have, however, also been observed in single case studies of the autobiographical recollections of amnesic patients and Korsakoff patients in particular; they may be consistent in content and accompanied by the subjective experience of remembering (Dalla Barba et al., 1990). Although no confabulatory battery was administered, neither informal conversations nor the background neuropsychological assessment or the interview data which 
were checked with the relatives indicated the presence in the present sample of the type of confabulatory responses described by Dalla Barba et al. Confabulations in autobiographical memory were not seen even in the Korsakoff patients, who were all well beyond the acute stages of the illness and therefore probably less likely to show such responses. It should also be noted that the memories were mainly tapped in an unconstrained manner in a free recall test, and more detailed prompting was not used. This procedure was chosen because of the frequent observation that distortions of memory mainly occur when subjects try to remember details that do not readily come to mind, while spontaneous autobiographical memory tends to be accurate (Neisser, 1988).

The present results for the Autobiographical Memory Interview by Kopelman et al. (1990) closely match the findings reported for amnesic subjects who were assessed with the original English version of the test (see Baddeley, 1990). The group of amnesic subjects showed severe deficits in the recollection of personal semantic facts and autobiographical incidents relative to control subjects. Semantic facts were better preserved than memory of autobiographical events and childhood memories were spared to a larger degree than recent memories. These results are consistent with many studies on autobiographical memory in amnesia (Tulving et al., 1988), and they confirm the presence of retrograde amnesia in the present sample, in addition to the pronounced anterograde amnesia documented by the neuropsychological assessment.

Despite the severe impairment on the Autobiographical Memory Interview which mainly assessed memory of relatively neutral events, recollection of emotionally flavoured autobiographical events showed some degree of preservation. Amnesic patients and control subjects remembered a similar number of personal events associated with pain, happiness or fear, even though the memories of the amnesics were much less detailed. This pattern is reminiscent of the analysis of autobiographical memory of brain-damaged patients by McCarthy and Warrington (1990) who noted that amnesics were able to remember a basic outline of their personal history, without being able to describe past events in much detail. Within this context, Baddeley (1990) referred to the "clouded" autobiographical memory of amnesics and to their problems of retrieving stored personal information.

Several features of the autobiographical memory performance of the amnesic patients are noteworthy. First, it is well known that negative emotional states at retrieval may affect memory performance in gen- eral and the type of experiences that are remembered (e.g. Bower, 1983; Depulta et al., 1993). As the amnesic patients did not differ in their affect and arousal ratings from controls, it is unlikely that mood may have had a considerable influence on recollection. Second, some authors have related the ability to recall affective memories to a capacity for mental imagery (Brewer, 1986; Robinson, 1992). In the present study, amnesic patients were able to describe imagery of personal experiences of pain and fear in detail similar to control subjects, which is not surprising, as no memory instruction was given. There is no obvious explanation for the somewhat reduced detail in relation to the description of happy situations. At least for negative experiences, both groups did not seem to differ greatly in the capacity for mental imagery.

One interesting feature of the autobiographical memory of amnesics concerns the finding that memory for pain appeared to be somewhat better preserved than memories for situations associated with happiness or fear. While a large proportion of all recollections in the control subjects were vivid and elaborate, the amnesics gave detailed descriptions in a considerable number of painful recollections, but less so in recollections of personal events associated with fear or happiness. This is not meant to imply that the pain memories of the amnesic patients were entirely normal. The amnesics remembered significantly less detail about their personal experience (affective and sensory details or thoughts) of the pain-related situations than the control subjects. Although the comparison of the number of contextual details did not approach significance in a non-parametric test, inspection of Table II indicates that the amnesics remembered only about $60 \%$ of the number of details of the control subjects. This pattern clearly indicates that the pain-related memories were not as vivid as those of the normal subjects. However, analyses in terms of the deficit relative to control subjects suggested that the pain-related recollections of the amnesics tended to be less impaired than the memories associated with happiness or fear. For six of the 10 amnesic patients, all pain-related memories were more elaborate, i.e. they were qualified by at least two details. In the categories of happiness or fear, the effect that all memories were more detailed was only seen in one amnesic patient. Further inspection of individual data did not reveal any clear pattern of differential performance of patients with differently located lesions, e.g. the Korsakoff patients were no more impaired at remembering emotional events than were the patients with more selective lesions. Taken together, these results suggest that the pain memories 
of amnesic patients were not entirely normal, but less impaired than memories of fear- or happiness-related information or the more neutral information that is assessed in the Autobiographical Memory Interview. In the latter test the scores of the amnesics lay at least two standard deviations below the means of the control subjects for all time periods.

A likely explanation for the more detailed recollections of painful personal experiences in amnesics relates to the hypothesis that memory for pain differs from memory for emotional events associated with fear and happiness because it has strong sensory-discriminative in addition to affective-evaluative components (see Flor et al., 1996). This interpretation is supported by a detailed analysis of the content of the control subjects' reports; the small number of elements reported by the patients precluded any further analysis. In the initial analysis, contextual and personal experience elements were analysed separately, and cognitive, affective and sensory items were pooled in the 'personal experience' category. A separate analysis of the personal experience items indicated that control subjects reported a similar number of affective-evaluative and sensory elements when describing painful events (means: 1.5 and 1.1 items), but there were more affective and hardly any sensory items when happy (means: 1.2 and 0.1 items) or fear-associated events (means: 1.1 and 0.4 items) were described. According to the model by Johnson (1990), personal experiences create entries into three memory subsystems, the sensory, perceptual and reflective systems, which together determine autobiographical memory. Amnesic patients show largely intact perceptual and sensory subsystems (Johnson et al., 1985), and emotional experiences such as fear are thought to be represented in the perceptual-evaluative subsystem, as fear may be closely tied to perceptual features of the event. It is conceivable that painful incidents may lead to better retention in amnesics because the sensorydiscriminative and the affective-evaluative aspects of painful experiences are encoded in both, the sensory and the perceptual memory subsystems, while happy or fear-related events would mainly enter the perceptual subsystem only. Painful experiences would thus be more richly encoded than experiences associated with the other categories and might therefore be more resistant to the disruption of memory associated with organic amnesia. Deficient entries into the reflective subsystem (Johnson and Chalfonte, 1994) would account for the general impairment of amnesics in recalling details about the personal experience of all emotional events. It is also possible that endorphin release during encoding of painful experiences may contribute to their better retention (see Izquierdo and
Netto, 1985), but the exact nature of the modulatory effect of hormones in memory formation is currently unclear.

With respect to childhood memories, it is interesting that - - similar to the results seen in the Autobiographical Memory Interview - a large proportion of the incidents described by the amnesic patients during free recall were experiences dating back to childhood. This was particularly striking for memory of pain where amnesics showed significantly more early memories than control subjects, when recollections were tapped in an unconstrained manner. As recently pointed out, reactivation may underlie the better retention of early autobiographical memories in amnesia (Johnson and Chalfonte, 1994). Talking or thinking about events may aid in preserving the subjective qualities of such experiences and thereby distinguish them from more abstract memories (Rubin and Kozin, 1984; Johnson and Chalfonte, 1994). The amnesic patients who participated in this study did remember events associated with strong emotions, but were impaired at remembering contextual details and particularly impaired in remembering any personal thoughts or feelings associated with these incidents. The former type of memory shows some parallel to retention of personal semantic facts, while the latter is reminiscent of impaired memory of episodes. Consistent with the concept of reactivation, more than $90 \%$ of all emotionally flavoured recollections of the amnesics came from the pre-morbid period, and salient personal events (such as a car accident or a first date) may have been repeatedly talked about with other people involved both before and after the incident which caused amnesia. Such memories may have developed the quality of a semantic memory, while the personal experience is usually rehearsed internally. As Johnson and Chalfonte (1994) pointed out, the inability of amnesic patients to mentally rehearse personal experiences impairs the maintenance of those aspects of autobiographical incidents that make them unique. In conclusion, some distinction between general semantic facts and personal experiences may also apply to autobiographical memory of emotionally flavoured life events.

Taken together, the present results indicate that the memory of amnesic patients may be characterized by relative sparing of autobiographical memories with a strong emotional flavour. These memories are, however, generally not as vivid and detailed as the memories of control subjects. Memory for pain appears to be less impaired than memories of other types of emotional experiences, which may relate to the combined sensory and affective qualities and the 
richer encoding of painful experiences compared to other personal events.

\section{Acknowledgements}

This research was supported by the Deutsche Forschungsgemeinschaft (DFG; Bi 195/24-1). We wish to thank Hans Markowitsch for providing us with his German-language adaptation of the Autobiographical Memory Interview.

\section{REFERENCES}

Baddeley A (1990) Human Memory: Theory and Practice. Allyn and Bacon, Boston.

Baddeley A and Wilson BA (1986) Amnesia, autobiographical memory and confabulation. In: Autobiographical Memory (Ed. DC Rubin), pp. 225-252. Cambridge University Press, Cambridge.

Benton AL (1955) The Revised Visual Retention Test. Psychological Corporation, New York.

Böcher W (1963) Erfahrungen mit dem Wechslerschen Gedächtnistest (Wechsler Memory Scale) bei einer deutschen Versuchsgruppe von 200 normalen Vpn. (Experiences with the Wechsler Memory Scale in a German sample of 200 normal subjects). Diagnostica, 9, 56-68.

Bond A and Lader M (1974) The use of analogue scales in rating subjective feelings. British Journal of Medical Psychology, 47, 211-218.

Bower GH (1983) Affect and cognition. Philosophical Transactions of the Royal Society, London, 302, 387-402.

Brewer WF (1986) What is autobiographical memory? In: Autobiographical Memory (Ed. DC Rubin), pp. 25-49. Cambridge University Press, Cambridge.

Brown RG, Marsden CD, Quinn N and Wyke MA (1984) Alterations in cognitive performance and affect-arousal during fluctuations in motor function in Parkinson's disease. Journal of Neurology, Neurosurgery and Psychiatry, 47, 454-465.

Butters N and Cermak LS (1986) A study of the forgetting of autobiographical knowledge: Implications for the study of retrograde amnesia. In: Autobiographical Memory (Ed. DC Rubin), pp. 253-272. Cambridge University Press, Cambridge.

Cahill L, Prins B, Weber M and McGaugh JL (1994) Betaadrenergic activation and memory for emotional events. Nature, 371, 702-704

Christianson SA and Loftus EF (1990) Some characteristics of people's traumatic memories. Bulletin of the Psychonomic Society, 28, 195-198.

Claparede E (1911) Recognition et moiite. Archives de Psychologie, 11, 79-90.

Conway MA (1990) Autobiographical Memory: An Introduction. Open University Press, Milton Keynes.

Dahl G (1972) Reduzierter Wechsler Intelligenztest. (Short version of the Wechsler intelligence test). Hain, Meisenheim.

Dalla Barba G, Cipolotti L and Denes G (1990) Autobiographical memory loss and confabulation in Korsakoff's syndrome: A case report. Cortex, 26, 525-534.

Daum I, Ackermann H, Schugens MM, Reimold C, Dichgans J and Birbaumer N (1993) The cerebellum and cognitive functions in humans. Behavioral Neuroscience, 107, $411-419$.
Depulta D, Singh R and Pomara N (1993) Aging, emotional states and memory. American Journal of Psychiatry, 150, 429-434.

De Renzi E, Liotti $M$ and Nichelli P (1987) Semantic amnesia with preservation of autobiographical memory: A case report. Cortex, 23, 575-597.

Erskine A, Morley S and Pearce S (1990) Memory for pain: A review. Pain, 41, 255-265.

Flor H, Knost B and Birbaumer N (1996) Autobiographical memory for pain in chronic pain patients and subjects at high risk for chronicity. Submitted for publication.

Hunter M, Philips C and Rachman S (1979) Memory for pain. Pain, 6, 35-46.

Izquierdo I and Netto CA (1985) Role of beta-endorphin in behavioral regulation. Annals of the New York Academy of Sciences, 444, 162-177.

Johnson MK (1990) Functional forms of human memory. In: Brain Organization and Memory (Eds JL McGaugh, NM Weinberger and G Lynch), pp. 106-134. Oxford University Press, Oxford.

Johnson MK and Chalfonte BL (1994) Binding complex memories: The role of reactivation and the hippocampus. In: Memory Systems 1994 (Eds DL Schacter and E Tulving), pp. 311-350. MIT Press, Cambridge.

Johnson MK, Kim JK and Risse G (1985) Do alcoholic Korsakoff's syndrome patients acquire affective reactions? Journal of Experimental Psychology: Learning Memory and Cognition, 11, 793-820.

Kopelman MD, Wilson BA and Baddeley AD (1990) Autobiographical Memory Interview. Thames Valley Test Company, Bury St Edmunds.

Linton M (1975) Memory for real-world events. In: Explorations in Cognition (Eds DA Norman and DE Rumelhart), pp. 376-404. Freeman, San Francisco.

Markowitsch HJ (1994) Effects of emotion and arousal on memory processing by the brain. In: Memory, Learning and the Brain (Ed. J Delacour), pp. 210-240. World Scientific Publication Corporation, Singapore.

Markowitsch HJ, Calabrese P, Haupts M, Durwen HF, Liess J and Gehlen W (1993) Searching for the anatomical basis of retrograde amnesia. Journal of Clinical and Experimental Neuropsychology, 15, 947-967.

MacKinnon DF and Squire LR (1989) Autobiographical memory and amnesia,. Psychobiology, 17, 247-256.

McCarthy RA and Warrington EK (1990) Cognitive Neuropsychology. A Clinical Introduction. Academic Press, London.

Neisser U (1988) Time present and time past. In: Practical Aspects of Memory. Current Research and Issues (Eds M Gruneberg, PE Morris and RN Snykes), pp. 545-560, Wiley, Chichester.

Nelson K (1989) Remembering. A functional developmental perspective. In: Memory. Interdisciplinary Approaches (Eds PR Solomon, Goethals, CM Kelley and BR Stephens), pp. 127-150. Springer, New York.

Osterrieth P (1944) Le test de copie d'une figure complexe. Archives de Psychologie, 30, 205-256.

Robinson JA (1992) Autobiographical Memory. In: $A s-$ pects of Memory. The Practical Aspects (Eds M Gruneberg and P Morris), pp. 223-251. Routledge, London.

Rubin DC and Kozin M (1984) Vivid memories. Cognition, 16, 81-95. 
Squire LR (1987) Memory and Brain. Oxford University Press, Oxford.

Tulving E, Schacter DL, McLachlan DR and Moscovitch M (1988) Priming of semantic autobiographical knowledge: A case study of retrograde amnesia. Brain and Cognition, 8, 3-20.
Wagenaar WA (1986) My memory: A study of autobiographical memory over six years. Cognitive Psychology, 18, 225-252.

Zola-Morgan S and Öberg RGE (1980) Recall of life experiences in an alcoholic Korsakoff patient: A naturalistic approach. Neuropsychologia, 18, 549-557. 


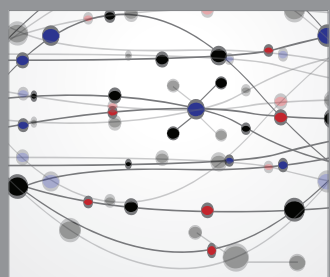

The Scientific World Journal
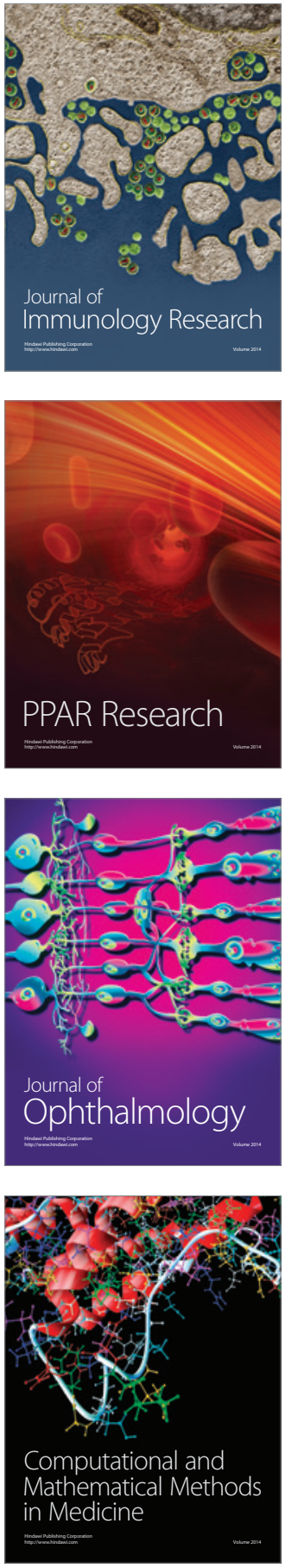

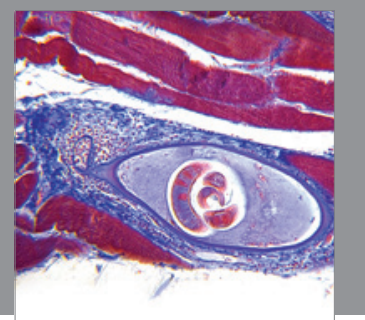

Gastroenterology

Research and Practice
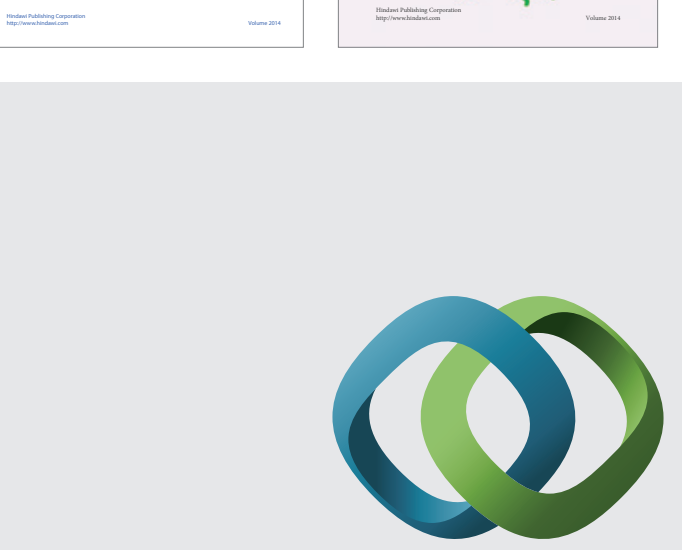

\section{Hindawi}

Submit your manuscripts at

http://www.hindawi.com
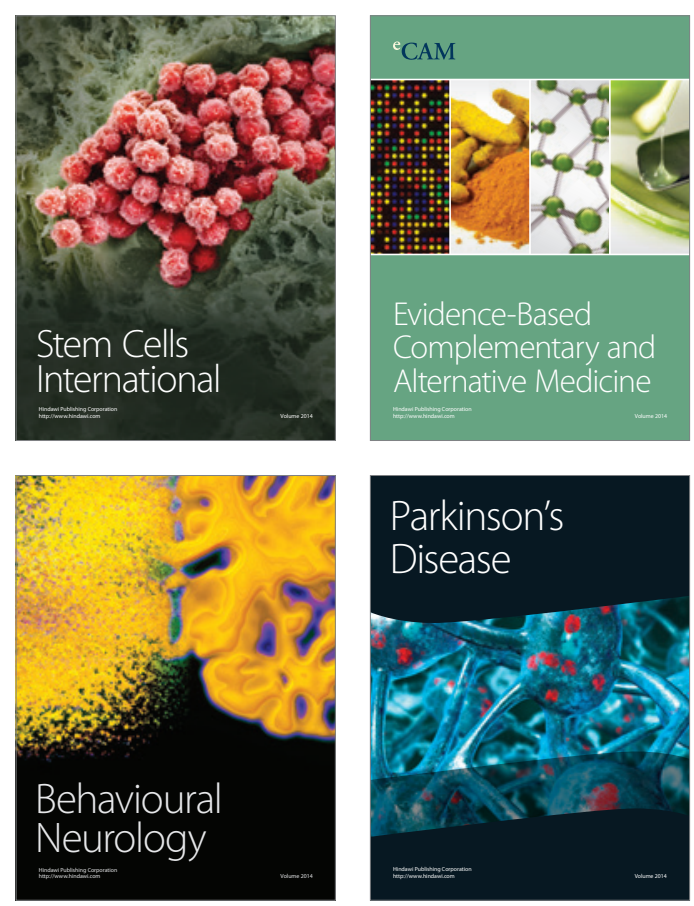

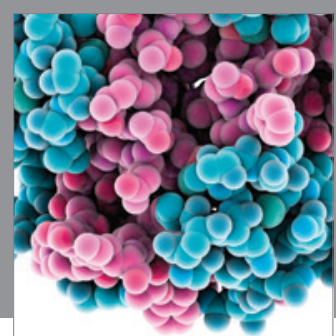

Journal of
Diabetes Research

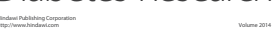

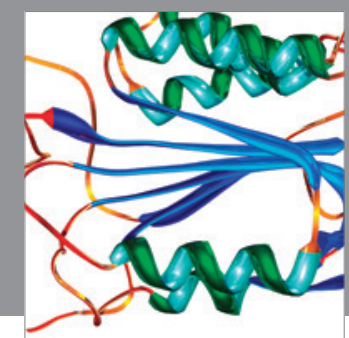

Disease Markers
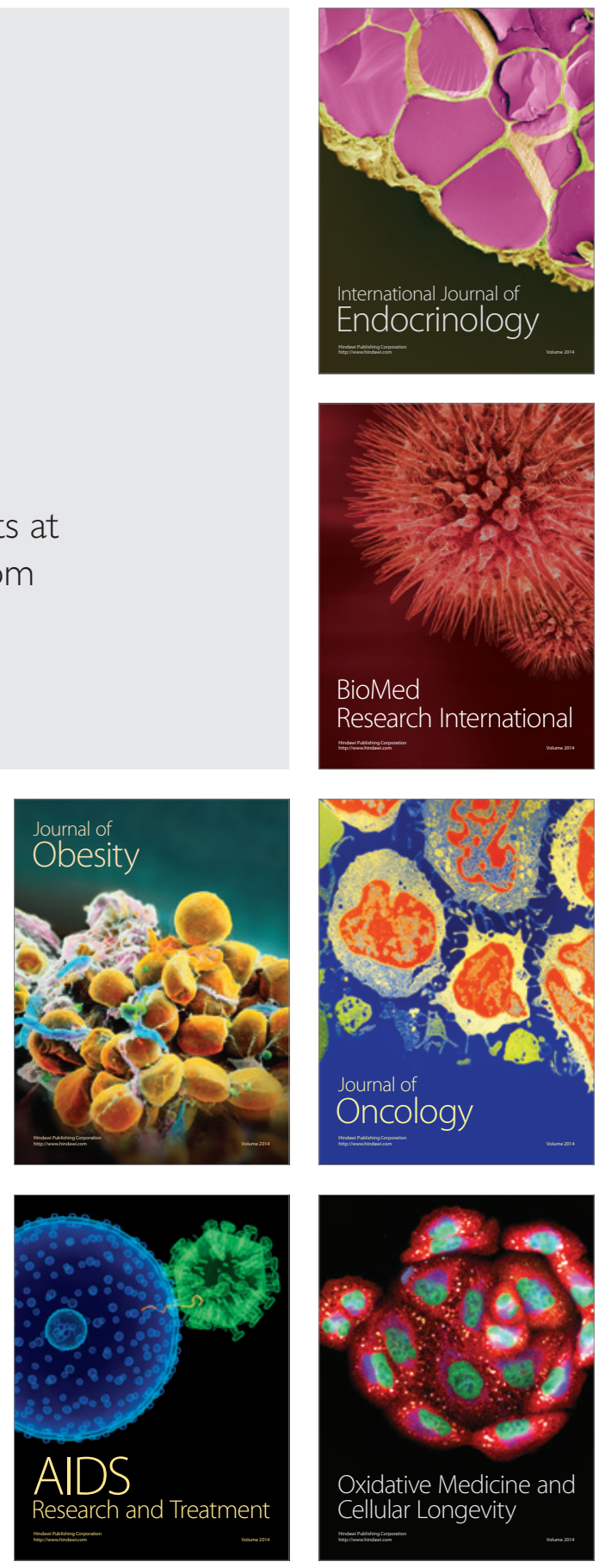